\title{
EFEITO DO PROBIÓTICO NA RESPOSTA IMUNE HUMORAL EM BOVINOS
}

Luis Eduardo Almeida, Sandra Cristina Genaro, Thaís Cristina Geroti, Neuza Frazatti Galina, Rogério Giuffrida, Paulo Eduardo Pardo

Mestrado em Ciência Animal da UNOESTE, Presidente Prudente - SP. E-mail: eduardopardo@unoeste.br.

\section{RESUMO}

Este estudo avaliou o efeito da suplementação do probiótico adicionado à mistura mineral na resposta imune humoral em bovinos vacinados com uma única dose de vacina antirrábica. Quarenta bovinos machos, Nelore, com idade de 12 meses, foram divididos aleatoriamente em 2 grupos (20 bovinos/grupo): grupo controle (GC) com 70 gramas de suplemento mineral/animal/dia e grupo probiótico (GP) com 70 gramas de suplemento mineral/animal/dia adicionado de 4 gramas de probiótico/animal. Os títulos individuais de anticorpos neutralizantes para raiva foram determinados por meio da técnica desoroneutralização baseada no Rapid Fluorescent Focus Inhibition Test (RFFIT) e no Fluorescent InhibitioMicrotest (FIMT). Não houve diferenças estatísticas significativas entre as médias de concentrações séricas entre os grupos, concluindo que a administração de probiótico não interferiu na resposta imune humoral antirrábica.

Palavras-chave: probióticos; raiva; ruminantes.

\section{EFFECT OF PROBIOTICS IN THE HUMORAL IMMUNE RESPONSE IN CATTLE}

\begin{abstract}
This study evaluated the effect of probiotic supplementation on mineral mixture to the humoral immune response in cattle vaccinated with a single dose of rabies vaccine. Forty steers, Nellore, aged 12 months were randomly divided into 2 groups (20 animals / group): control group (CG) with 70 grams of mineral / animal / day and probiotic group (GP) with 70 grams of supplement mineral added with 4 grams of probiotic / animal. The individual titles of neutralizing antibodies were determined by neutralization technique based on the Rapid Fluorescent Focus Inhibition Test (RFFIT) and Fluorescent Inhibition Microtest (FIMT). There were no statistic significant differences between the mean serum concentrations between groups, concluding that the administration of probiotics does not interfere with the humoral immune response rabies.
\end{abstract}

Keywords: probiotic; rabies; ruminant. 


\section{INTRODUÇÃO}

A raiva é uma enfermidade infecciosa viral do sistema nervoso central dos mamíferos, causada por um vírus neurotrópico, RNA, da Ordem Mononegavirales, Família Rhabdoviridae e do Gênero Lyssavirus (GIOMETTI et al., 2006; ACHKAR et al., 2007; CONSALES; BOLZAN, 2007; CAZELLA et al., 2009), onde no Brasil, o principal agente transmissor do vírus rábico é o morcego hematófago Desmodus rotundus (ALBAS et al., 2006; SCHEFFER et al., 2007).

A vacinação é o melhor método de controle da raiva por ser efetivo e de baixo custo (ALBAS et al., 2005, 2006, CAZELLA et al., 2009, MARIA et al, 2009), portanto, faz-se necessária a busca por alternativas que aumentem a eficácia da vacinação contra o vírus rábico. $O$ uso de adjuvantes tem revelado bons resultados na restauração da resposta imunitária e na potencialização de vacinas em relação a diversos agentes patógenos (REIS, 2008; CAZELLA et al., 2009).

Uma das estratégias para aumentar a resposta imunológica dos animais à imunidade induzida ou às infecções provocadas por vírus ou bactérias é o uso de probióticos (ARENAS et al., 2009; FERREIRA et al., 2009; PENHA et al., 2011) ao suplemento mineral utilizado.

Probióticos são suplementos alimentares que contém microrganismos vivos, que administrado em quantidade adequada, produzem efeitos benéficos para a saúde do hospedeiro (animais e seres humanos) (MILES, 2007; HOLANDA et al., 2008), promovendo a saúde e não a cura de doenças (MORAES; COLLA, 2006; KARKOW et al., 2007; OMGE, 2008; FERREIRA et al., 2009). É definido também como "uma preparação ou produto contendo determinado (s) microrganismo (s) viável (eis), em quantidades suficientes, que alteram a microbiota em um determinado compartimento do hospedeiro exercendo, deste modo pelo menos um efeito benéfico". Estes microrganismos são mundialmente utilizados como preparações farmacêuticas ou produtos fermentados (MARTINS et al., 2005; PARDO; REIS, 2008).

A eficácia da utilização dos probióticos é estritamente dependente da quantidade e características das cepas de microrganismos utilizados na elaboração do produto como aditivo alimentar. As espécies bacterianas mais comuns para o preparo são: Lactobacillus bulgaris, $L$. acidophilus, L. casei, L. lactis, L. salivarius, L. plantarium, L.reuteri, L. johonsie, Streptococcus thermophilus, Enderococcus faecium, E. faecalis, Bifidobacterium ssp., Bacillus subtilis, B. toyoi, Aspergillus oryzae e Saccharomyces cerevisiae (MATOS, 2008).

Para um produto probiótico apresentar a alegação de promoção de saúde, no seu rótulo, a Agência Nacional de Vigilância Sanitária (BRASIL, 2008), estabelece que a quantidade mínima viável da cultura deva estar entre $10^{8}$ a $10^{9}$ UFC (Unidades Formadoras de Colônias) por porção do produto (HOLANDA et al., 2008).

A grande vantagem da terapia com os probióticos é a ausência de efeitos secundários, como a seleção de bactérias resistentes. Os efeitos benéficos destes microrganismos são basicamente os mesmos da microbiota normal do corpo humano. O que se faz neste caso é a utilização, em grande quantidade, daqueles que possuem eficácia comprovada, podendo ser constituintes normais da microbiota, como é o caso das bifidobactérias e dos lactobacilos, ou não, como a levedura S. boulardii. Além do mais, uma das principais preocupações da Organização Mundial da Saúde é a implementação de novas terapias que não atuem como uma forte pressão seletiva, propiciando a geração de patógenos cada vez mais agressivos e resistentes (MARTINS et al., 2005). 
O estímulo do sistema imunológico ainda não está totalmente esclarecido (SILVA et al., 2006; PARDO; REIS, 2008). Essa ação imunoestimulante é atribuída às bactérias ácido láticas (CROSS, 2002), entre elas: Lactobacilus acidophilus, Bifidobacterium bifidum e Bifidobacterium longum (KOENEN et al., 2004).Várias pesquisas têm demonstrado que os probióticos estimulam a atividade fagocítica dos leucócitos (OYETAYO; OYETAYO, 2005), aumentam a proliferação de linfócitos $\mathrm{T}, \mathrm{a}$ atividade dos macrófagos e elevam a atividade das células Natural Killer (NK); ativam as células T Helper CD4+ subpopulação Th1 (OUWEHAND et al., 1999). Ainda modulam as bactérias da microflora intestinal, atuando no balanço Th1/Th2, promovendo o controle de processos infecciosos e imunológicos (NOGUEIRA; GONÇALVES, 2011). Aumentam também a produção de anticorpos e a secreção de mediadores químicos que estimulam o sistema imune (CROSS, 2002). Entre elas estão a produção de citocinas, interferon gama (IFN- $\gamma$ ), TNF, interleucina (IL) 1 , IL-2, IL-10 e a IL-12 (OUWEHAND et al., 1999).

Argumenta-se que a utilização de probióticos possa contribuir na promoção do crescimento animal, melhora na conversão alimentar (PENHA et al., 2011), maior absorção de nutrientes pelo controle da diferenciação e proliferação das células epiteliais, neutralização de fatores antinutricionais, melhora no metabolismo de carboidratos, cálcio e síntese de vitaminas, produção de enzimas microbianas para compensar atividades deficientes de enzimas do hospedeiro, eliminação ou controle de microrganismos patogênicos causadores de doenças subclinicas ou clinicas e estimulo da imunidade especifica ou não especifica no intestino. PNo entanto ainda são escassos e inconsistentes os estudos sobre a ação de microrganismos probióticos sobre os parâmetros ruminais e desempenho produtivo de ruminantes (MATOS, 2008; PENHA et al., 2011).

O objetivo desse estudo foi de avaliar o efeito da suplementação do probiótico sobre a concentração de anticorpos séricos em bovinos vacinados com uma única dose de vacina antirrábica.

\section{MATERIAL E MÉTODOS}

\section{Delineamento experimental}

O experimento foi desenvolvido nos meses de maio e outubro de 2010, durante 150 dias, no município de Jundiaí do Sul, PR, cuja latitude $23^{\circ} 26^{\prime} 13^{\prime \prime}$ sul e longitude 50¹4'52" oeste, estando a uma altitude de $520 \mathrm{~m}$. Utilizaram-se 40 bovinos, machos inteiros da raça Nelore (Bos indicus) com idade de, aproximadamente, 12 meses, divididos aleatoriamente em 2 grupos (20 bovinos/grupo), onde o grupo controle (GC) recebeu mistura mineral proteinada sem probiótico e no grupo probiótico (GP) os animais foram suplementados com mistura mineral proteinada adicionada de probiótico Proenzime ${ }^{\circledR}$.EMBRAUPEC, PARANAVAí. PARANÁ, BRASIL OS animais do GP consumiram $4 \mathrm{~g}$ de probiótico/animal/dia durante 0 período experimental. No dia zero do experimento, aplicou-se em todos os bovinos uma dose de $2 \mathrm{~mL}$ de vacina antirrábica produzida pelo Instituto Butantan, São Paulo, SP, Brasil; por via subcutânea.

A pastagem utilizada por ambos os grupos eram semelhantes na topografia $e$ composição botânica, sendo formados por Brachiaria brizantha. O sistema de pastejo adotado foi o extensivo.

\section{Análises laboratoriais}

As amostras de sangue dos bovinos foram colhidas nos dias 0, 75 e 150. O sangue foi colhido por meio da punção da veia jugular em tubos à vácuo sem anticoagulante, centrifugados 
a $2.500 \mathrm{rpm}$ por 10 minutos e as amostras de soro foram acondicionadas em tubos plásticos de 1,5 mL e armazenadas em freezer a $-20^{\circ} \mathrm{C}$ para posterior determinação do título de anticorpos neutralizantes anti-rábicos.

Os títulos de anticorpos neutralizantes antirrábicos foram determinados por meio da técnica de soroneutralização em células $\mathrm{BHK}_{21}$, teste esse, baseado no Rapid Fluorescent Focus Inhibition Test - RFFIT (SMITH et al., 1998) e no Fluorescent Inhibition Microtest - FIMT (ZALAN et al., 1979).

Utilizou-se um probiótico comercial devidamente registrado e aprovado pelo Ministério da Agricultura, Pecuária e Abastecimento (MAPA), composto por: amilase, celulase, protease, lipase, pectinase, Lactobacilus acidophilus, Estreptococus faecium, Bifedobacterium thermoplhilum, Bifedobacterium longum e zinco. Falar qual marca comercial, descrever fabricante e origem do produto.

A vacina anti-rábica utilizada foi produzida pelo Intituto Butantan, São Paulo, SP, Brasil.

\section{ANÁLISE ESTATÍSTICA}

Preliminarmente a análise dos dados empregou-se o teste de Shapiro-Wilk para verificar se os dados observados apresentaram distribuição gaussiana, pelo qual todas as variáveis foram consideradas como não paramétricas $(p<0,05)$. A seguir, os títulos sorológicos observados para cada grupo, aos 74 e 150 dias pós-vacinação, foram transformados em escores- $Z$ para determinar a existência de valores atípicos influentes (outliers) sendo classificados dentro desta categoria, as observações com valor de $Z>2,5$ (HAIR JUNIOR, 2005). Para complementar a análise de observações influentes recorreu-se também a avaliação gráfica por meio da construção de gráficos do tipo Box-plot.

A comparação dos títulos sorológicos entre os grupos controle e tratado, aos 74 e aos 150 dias, foi realizada pelo teste de MannWhitney. Os títulos sorológicos dentro de cada grupo, aos 74 e 150 dias pós-vacinação, foram comparados pelo teste de Wilcoxon para amostras relacionadas (PAGANO; GAUVREAU, 2004).

Considerando-se como ponto de corte para o título vacinal protetor o valor de 0,5 UI, as proporções de animais protegidos em cada grupo vacinado foram comparadas pelo teste exato de Fisher. Dentro de cada grupo, a proporção de animais imunizados contra raiva aos 74 e 150 dias foi comparada pelo teste de Qui-quadrado de MacNemar.

Todas as análises foram realizadas utilizando 0 pacote computacional Bioestat (AYRES et al., 2007), adotando-se nível de significância de 5\%.

\section{RESULTADOS E DISCUSSÃO}

No dia zero os soros dos animais não apresentaram anticorpos neutralizantes para a raiva, mostrando que os bovinos não haviam tido contato com o vírus rábico selvagem ou vacinal.

Os gráficos do tipo Box-plot referentes aos dois momentos observados para cada um dos três grupos estão representados na Figura 1, que permite observar a existência de cinco valores considerados como outliers e que foram determinantes para a adoção dos métodos estatísticos descritos acima. 


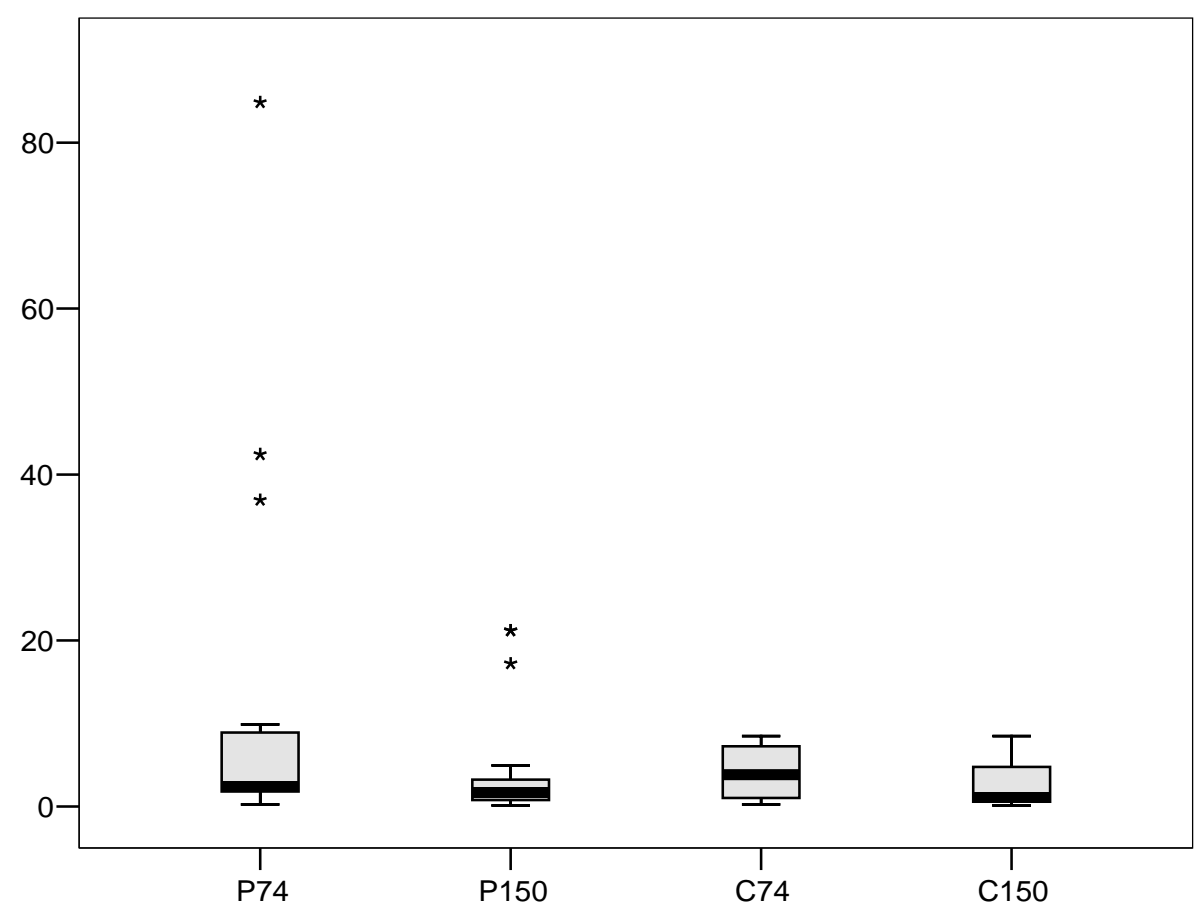

Figura 1. Comparação dos títulos soroneutralizantes (eixo y) pós-vacinação direcionados contra o vírus rábico vacinal cepa vírus Pasteur para os grupos de animais tratados com probiótico aos 74 (P74) e aos 150 dias (P150) e controles aos 74 (C74) e 150 dias (C150). As linhas no interior dos boxes denotam o segundo quartil (50\% dos dados - mediana), as linhas superiores, o terceiro quartil ( $75 \%$ dos dados) e as inferiores o primeiro quartil ( $25 \%$ dos dados). As linhas aplicadas indicam os limites dos valores extremos e os pontos externos a elas indicam os outliers.

$\mathrm{Na}$ Tabela 1 encontram-se os valores correspondentes ás médias geométricas para cada um dos momentos, considerando-se os dois grupos estudados. Foram observadas diferenças estatísticas significativas entre as médias dos títulos soroneutralizantes no grupo Probiótico do dia 74 ao dia 150 pós-vacinação (letras minúsculas diferentes na mesma linha), demonstrando que o uso contínuo de probiótico pode melhorar a imunização, porém não apresentaram diferenças estatísticas significativas entre os grupos do estudo (Valores na mesma coluna seguidos de letras maiúsculas iguais). Os resultados obtidos concordam o trabalho de Ferreira et al. (2009) onde avaliaram a resposta imune humoral antirrábica em bovinos utilizando vacina antirrábica e suplementação com probióticos e não encontraram diferenças estatísticas significativas entre as médias de concentrações séricas entre os grupos (Tabela 1),

Tabela 1. Médias geométricas de títulos de anticorpos $(\mathrm{UI} / \mathrm{mL})$ soroneutralizantes contra vírus rábico cepa vírus Pasteur mensurados aos 74 e 150 dias pós-vacinação, Presidente Prudente, SP, 2011.

\begin{tabular}{lll}
\hline Tratamento & 74 dias & 150 dias \\
\hline Probiótico & $3,176 \mathrm{Aa}$ & $2,775 \mathrm{Ab}$ \\
Controle & $1,571 \mathrm{Ab}$ & $1,479 \mathrm{Ab}$ \\
\hline
\end{tabular}

Valores na mesma coluna seguidos de letras maiúsculas diferentes e na mesma linha seguidos de letras minúsculas diferentes apresentam diferenças significativas $(p<0,05)$

$\mathrm{Na}$ Figura 2 a curva ilustrada

corresponde aos valores das médias geométricas 
de títulos sorológicos (UI/mL) nos dias zero, 74 e ilustrar o que a tabela 1 demonstra. 150 pós-vacinação. Essa figura é uma forma de

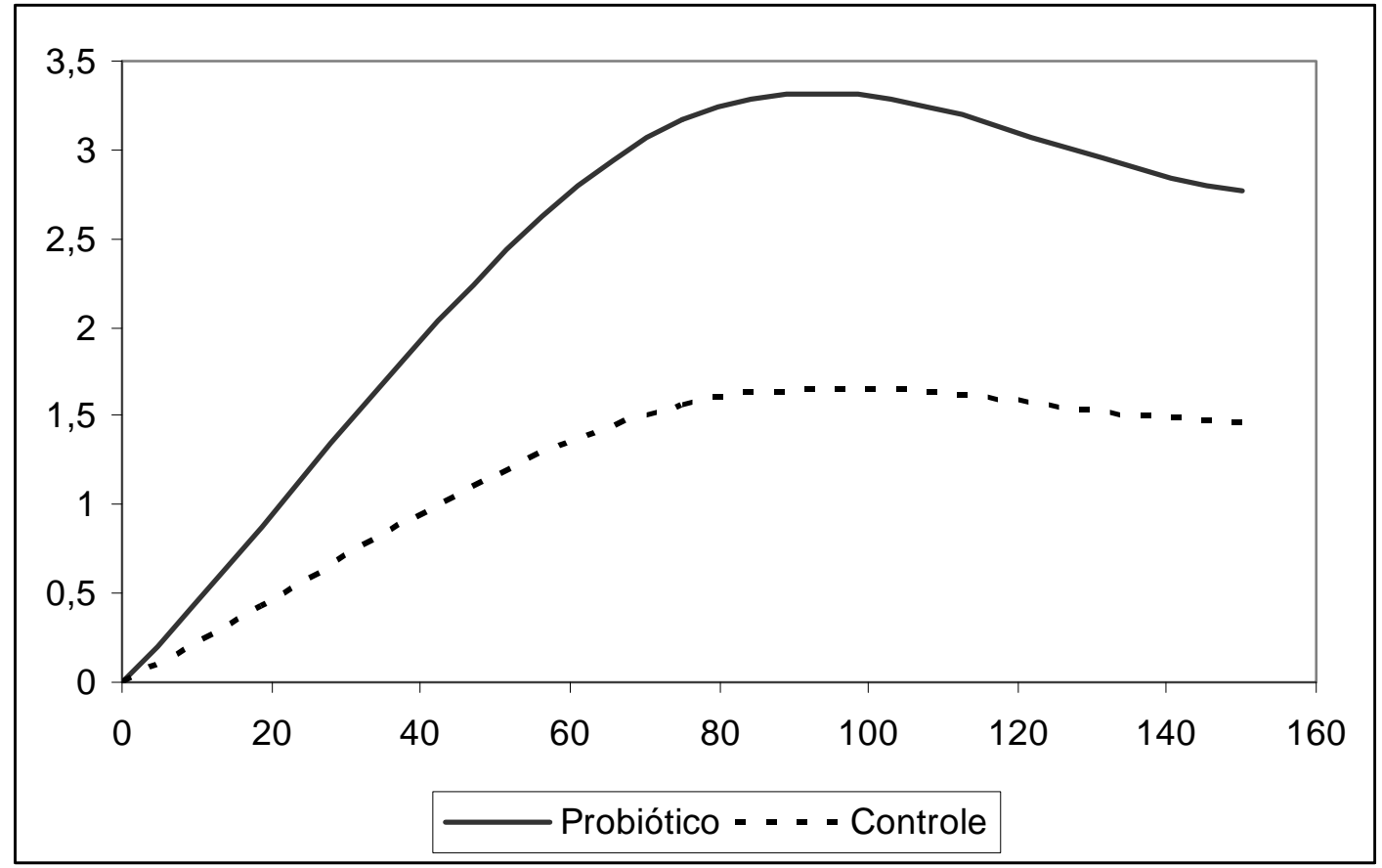

Figura 2. Média geométricas de anticorpos soroneutralizantes contra vírus rábico cepa vírus Pasteur (eixo y) em três momentos (0,74 e 150 dias) (eixo x), segundo tratamento utilizado (P-Probiótico, e C-Controle).

Neste estudo, não houve efeito da interação entre grupos experimentais e dias de observação.

$\mathrm{Na}$ tabela 2 podem ser observadas as proporções de animais com títulos soroneutralizantes considerados protetores para raiva (> 0,5 UI). As proporções de animais considerados imunes aos 74 e 150 dias não deferiram entre o grupo tratado e controle. Dentro de cada grupo também não foram observadas diferenças significativas entre os títulos sorológicos mensurados aos 74 e 150 dias ( $p$ $<0,05)$.

Tabela 2. Proporções de animais com títulos soroneutralizantes considerados protetores $(>0,5 \mathrm{UI} / \mathrm{mL})$ mensurados aos 74 e 150 dias pós-vacinação em dois grupos de bovinos, Presidente Prudente, SP, 2011.

\begin{tabular}{lllll}
\hline \multirow{2}{*}{ Grupos } & 74 dias & \multicolumn{3}{l}{150 dias } \\
\cline { 2 - 5 } & $>0,5$ & $<0,5$ & $>0,5$ & $<0,5$ \\
\hline Probiótico (GP) & $17(85 \%)$ & $3(15 \%)$ & $16(80 \%)$ & $4(20 \%)$ \\
Controle (GC) & $18(90 \%)$ & $2(10 \%)$ & $14(70 \%)$ & $6(30 \%)$ \\
\hline
\end{tabular}

Aos 74 dias do experimento, encontramos 85\% de animais protegidos contra o vírus rábico no GP, contra 90\% no GC. Porém aos 150 dias do experimento, o GP mostrou-se mais eficiente, apresentando $80 \%$ dos animais protegidos contra $70 \%$ do GC, justificando o efeito do estímulo ao sistema imunológico (ESPARZA; FRAGOSO,
2010; NOGUEIRA; GONÇALVES, 2011), atribuídos às bactérias ácido láticas (CROSS, 2002; SILVA et al., 2006; PARDO; REIS, 2008). As bactérias em questão potencializam as vacinas, com propriedades moduladoras da resposta imunológica, por aumento da produção de anticorpos, ativação de macrófagos, 
proliferação de células T e produção de interferon (ROSS, 2006).

Arenas et al. (2009), estudando o efeito da administração do probiótico Proenzime® para bovinos primovacinados contra a raiva relataram aumento significativo nos títulos de anticorpos antirrábicos nos bovinos, 30 e 60 dias após a vacinação.

$\mathrm{Na}$ Figura 3, ilustração da tabela 2, pode-se observar um gráfico de barras contendo as proporções de animais protegidos pela vacina, segundo o tratamento e a data de colheita do soro.

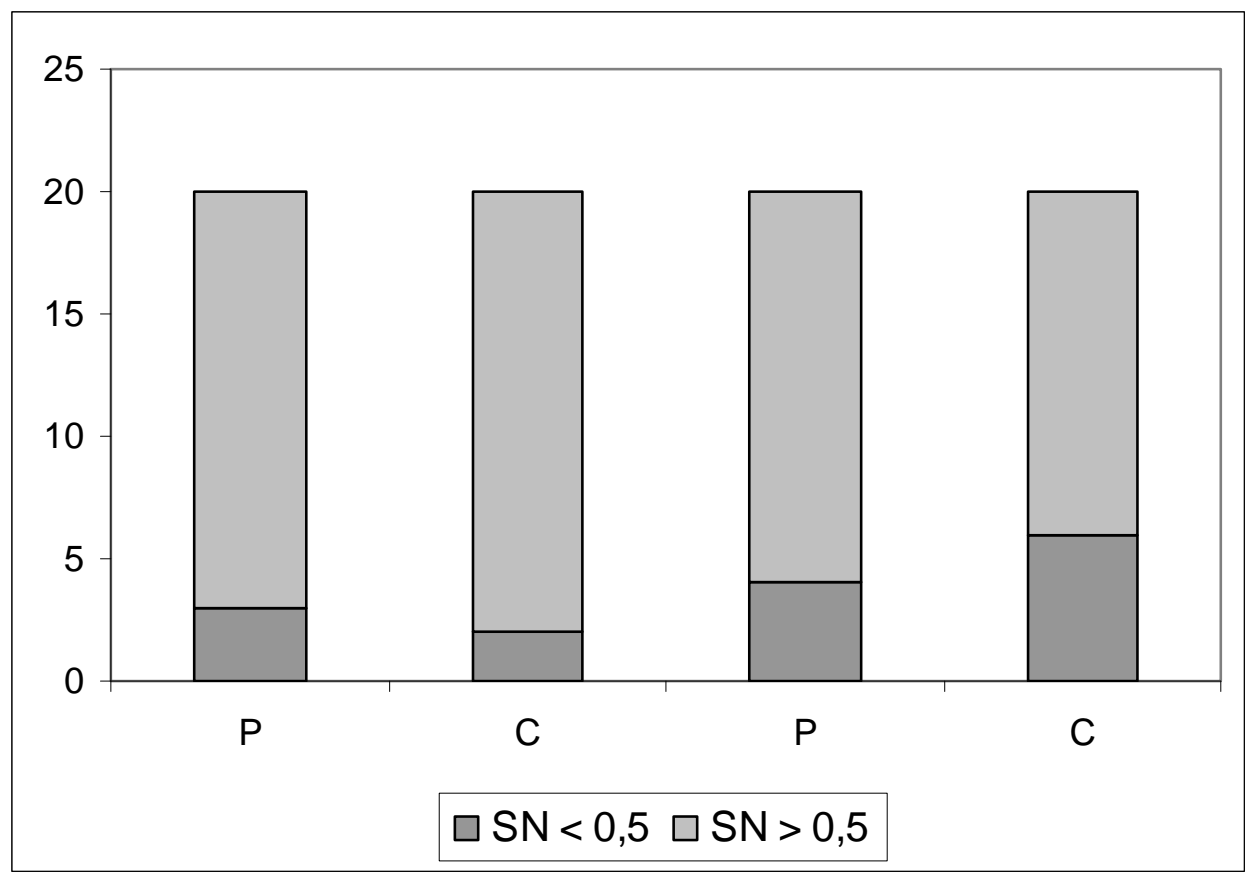

Figura 3. Animais vacinados (títulos soroneutralizantes superiores a $0,5 \mathrm{UI} / \mathrm{mL})(\mathrm{SN}>0,5)$ e animais (títulos inferiores a $0,5 \mathrm{UI} / \mathrm{mL})(\mathrm{SN}<0,5)$ (eixo y), segundo o tratamento com Probiótico $(\mathrm{P})$ e Controle $(\mathrm{C})$, aos 74 e 150 dias pós-vacinação (eixo x).

\section{CONCLUSÃO}

Às condições em que o experimento foi desenvolvido e de acordo como os resultados obtidos, pode-se concluir que a vacina antirrábica utilizada neste experimento teve eficiência em produzir e manter a soroconvesão nos bovinos primovacinados contra a raiva por 150 dias e que a administração de probiótico não interferiu na resposta imune humoral antirrábica.

\section{REFERÊNCIAS}

ACHKAR, S. M.; SINHORINI, I. L.; RIBEIRO, O. G.; CARRIERI, M. L.; CERETTA, R. S.; CONSALES, C. A. Immunopathology of rabies infection in mice selected for high or low acute inflammatory reaction. Journal of Venomous

\section{Animais and Toxins includin Tropical}

Diseases, v. 13, p. 39-55, 2007.

http://dx.doi.org/10.1590/S1678-

91992007000100003

ALBAS, A.; PARDO, P. E.; BREMER NETO, H. N.; GALLINA, M. F.; MOURÃO FUCHES, R. M.; SARTORI, A. Vacinação antirrábica em bovinos: Comparação de cinco esquemas vacinais.

Arquivos do Instituto Biológico, v. 72, p. 153159, 2005.

ALBAS, A.; FONTOLAN, O. L.; PARDO, P. E.; BREMER NETO, H.; SARTORI, A. Interval between first dose and booster affected antibody production in cattle vaccinated against rabies. 


\section{Journal of Venomous Animals and Toxins} including Tropical Diseases, Botucatu, v. 12, n. 3, p. 476-486, 2006.

http://dx.doi.org/10.1590/S1678-

91992006000300010

ARENAS, S. E.; REIS, L. S. L. S.; FRAZATTI-

GALLINA, N. M.; FUJIMURA, S. H.; BREMER NETO, H.; MESSAS, A. C. e PARDO, P. E.

Probiotic increase the antirabies humoral immune Response in bovine. Archivos de Zootecnia, v. 58, n. 224, p. 733-736, 2009.

http://dx.doi.org/10.4321/S0004-

05922009000400011

AYRES, M., AYRES JÚNIOR, M., AYRES, D. L., SANTOS, A. A. BIOESTAT - Aplicações estatísticas nas áreas das ciências biomédicas. Belém: Ong Mamiraua, 2007.

BRASIL. Resolução RDC $n^{\circ}$ 2, de 07 de Janeiro de 2002. Regulamento técnico de substâncias bioativas e probióticos isolados com alegação de propriedades funcional e ou de saúde.

Diário Oficial da União; Poder executivo de 07 de Janeiro 2002. Disponível em

http://www.anvisa.gov.br/alimentos/comissoes/tec no regula.htm. Acessado em 19 de Fevereiro de 2010.

CAZELLA, L. N.; PARDO, P. E.; FRAZATTIGALLINA, N. M.; REIS, L. S. L. S. Effect of levamisole on the humoral immune response against rabies in cattle. Veterinary Record, $n$. 165, p.722-723, 2009.

http://dx.doi.org/10.1136/vr.165.24.722

CONSALES, C. A.; BOLZAN, V. L. Rabies review: Immunopathology, clinical aspects and treatment. Journal of Venomous Animals and Toxins including Tropical Diseases, v. 13, n. 1, p. 5-38, 2007. http://dx.doi.org/10.1590/S1678-

91992007000100002

CROSS, M. L. Microbes versus microbes:

immune signals generated by probiotic lactobacilli and their role in protection against microbial pathogens. FEMS Immunology and Medical Microbiology (Federation of European Microbiological Societies), Amsterdam, 34(4): 245-253, 2002.

ESPARZA, J. A.; FRAGOSO, R. L. S. ¿Qué sabe Ud. acerca de... los probióticos? Revista

Mexicana de Ciências Farmacêuticas, n. 41, p. 60-63, 2010.

FERREIRA, L. A.; PARDO, P. E; FRAZATTIGALLINA, N. M.; MOURÃO-FUCHES, R. M.; VENTINI, D. C.; KRONKA, S. N.; ARENAS, S. E.; REIS, L. S. L. S. Avaliação da vacinação antirábica e da suplementação com probiótico na resposta imune humoral em bovinos. Semina: Ciências Agrárias, Londrina, v. 30, n. 3, p. 655660, jul./set., 2009.

GIOMETTI, J.; CHIACCHIO, S. B.; ALBAS, A.; PARDO, P. E.; BREMER NETO, H.; GIOMETTI, A. I. e REIS, L. S. L. S. Influência da suplementação com crômio na resposta imune humoral antirrábica em bovinos. Arquivos do Instituto Biológico, v. 73, n. 4, p. 421-427, 2006. HAIR JUNIOR, J. F.; ANDERSON, R. E.; TATHAM, R. L.; BLACK, W. C. Análise Multivariada de Dados. 5. ed. Porto Alegre: Bookman, 2005. p. 49-88.

HOLANDA, L. B.; ANTUNES, A. E.; DEL SANTO, R.; MUNIZ, V. O. Conhecimento sobre probióticos entre estudantes de uma instituição de ensino superior. Revista Acadêmica Digital do Grupo POLIS Educacional, v. 04, n. 05, jul./dez. 2008. KARKOW, F. J. A.; FAINTUCH, J.; KARKOW, A. G. M. Probióticos: perspectivas médicas. Revista da AMRIGS, Porto Alegre, v. 51, n. 1, p. 38-48, jan.-mar. 2007.

KOENEN, M. E.; KRAMER, J.; VAN DER HULST, R.; HERES, L.; JEURISSEN, S. H.; BOERSMA, W. J. Immunomodulation by probiotic lactobacilli in layer-and-meat-type chickens. British Poultry 
Science, v. 45, p. 355-366, 2004.

http://dx.doi.org/10.1080/00071660410001730851

MARIA, E. K.; PARDO, P. E.; FRAZATTI-

GALLINA, N. M.; PAOLI, R. L.; MOURÃO-

FUCHES, R. M.; REIS, L. S. L. S. 2009.

Suplementação com zinco não influencia a resposta imune humoral antirrábica em bovinos.

Archivos de Zootecnia, v. 58, supl. 1, p. 605608, 2009.

MARTINS, F. D.; BARBOSA, F. H. F.; PENNA, F. J.; ROSA, C. A.; NARDI, R. M. D.; NEVES, M. J.; NICOLI, J. R. Estudo do potencial probiótico de linhagens de Saccharomyces cerevisiae através de testes in vitro. Revista de Biologia e Ciências da Terra, v. 5, n. 2, $2^{\circ}$ sem., 2005.

MATOS, B. C. Uso de aditivos na pecuária leiteira: revisão. PUBVET, v. 2, n. 9, mar. 2008.

MILES, L. Are probiotics beneficial for health? Journal Compilation, British Nutrition Foundation Nutrition Bulletin, v. 32, p. 2-5, 2007.

http://dx.doi.org/10.1111/j.1467-

3010.2007.00611.x

MORAES F. P.; COLLA L. M. Alimentos funcionais e nutracêuticos: definições, legislação e benefícios à saúde. Revista Eletrônica de Farmácia, v. 3, n. 2, p. 99-112, 2006.

NOGUEIRA, J. C. R.; GONÇALVES, M. C. R. Probiotics in allergic rhinitis. Brazilian Journal of Otorhinolaryngology, v. 77, n. 1, jan./fev. 2011. OMGE. Organização Mundial de Gastroenterologia. Guias práticas: probióticos e prebióticos. [s.l].: [s.n.], 2008.

OYETAYO, V. O.; OYETAYO, F. L. Potencial of probiotics as biotherapeutic agents targenting the innate system. African Journal of biotechnology, v. 4, n. 2, p. 123-127, 2005.

OUWEHAND, A. C.; KIRJAVAINEN, P. V.; SHORTT, C.; SALMINEN, S. Probiotics: Mechanisms and estabilished effects.
International Dayry Journal, v. 9, n. 1: 43-52, 1999. http://dx.doi.org/10.1016/S09586946(99)00043-6

PAGANO, M., GAUVREAU, K. Princípios de bioestatística. 2. ed. São Paulo: Pioneira Thomson Learneing, 2004.

PARDO, P. E; REIS, L. S. L. S. Nutrientes e nutracêuticos em grandes animais. In:

ANDRADE, S. F. Manual de terapêutica veterinária. 3. ed. São Paulo: Rocha, 2008. p. 808-814.

PENHA, L. A. C.; PARDO, P. E.; KRONKA, S. N.; REIS, L. S. L. S.; OBA, E.; BREMER-NETO, H. Effects of probiotic supplementation on liveweight gain and serum cortisol concentration in cattle.

Veterinary Record, v. 168, p. 538, 2011.

http://dx.doi.org/10.1136/vr.d589

REIS, L. S. L. S.; FRAZATTI-GALLINA, N. M.; LIMA, P. R.; GIOFFRIDA, R.; ALBAS, A.; OBA, E. PARDO, P.E. Efficiency of Matricaria chamomilla $\mathrm{CH} 12$ and number of doses of rabies vaccine on the humoral immune response in cattle. Journal of Veterinary Science, v. 9, n. 4, p. 433-435, 2008. http://dx.doi.org/10.4142/jvs.2008.9.4.433

ROOS, T. B. Efeito de Saccharomyces boulardii e Bacillus cereus var. toyoi na resposta imune humoral de cordeiros vacinados contra Escherichia coli e Herpes Vírus Bovino-5. 2006. 66f. Dissertação (Mestrado em Veterinária) Faculdade de Veterinária, Universidade Federal de Pelotas, Pelotas, 2006.

SCHEFFER, K. C.; CARRIERI, M. L.; ALBAS, A.; SANTOS, H. C. P.; KOTAIT, I.; ITO, F. H. Vírus da raiva em quirópteros naturalmente infectados no Estado de São Paulo, Brasil. Revista de Saúde Pública, v. 41, n.3, p. 389-395, 2007. http://dx.doi.org/10.1590/S003489102007000300010 SILVA, C. A.; HOSHI, E. H.; PACHECO, G. D.; BRIGANÓ, M. V. Avaliação de probióticos 
(Pediococcus acidilactici e Bacillus subtilis) após o desmame e efeitos no desempenho dos leitões.

Semina: Ciências Agrárias, v. 27, n. 1, p. 133-

140, 2006.

SMITH, J. S.; Y AGER, P. A.; BAER, G. M. A

rapid fluorescent focus inhibition test (RFFIT) for

determining rabies virusneutralizing antibodies. In:

MESLIN F. X.; K APLAN, M. M.; KOPROWISKI,

$\mathrm{H}$. (eds.). Laboratory techiniques in rabies.

Geneva: WHO, 1998. p. 181-192.

ZALAN, E.; WILSON, C.; PUKITIS, D. A microtest for the quantitative of rabies virus neutralizing antibodies. Journal of Biological

Standardization, n. 3, p. 213-220,1979.

http://dx.doi.org/10.1016/S0092-1157(79)80024-4 